\title{
PAD4-Dependent Antibiosis Contributes to the ssi2- Conferred Hyper-Resistance to the Green Peach Aphid
}

\author{
Joe Louis, ${ }^{1}$ Queena Leung, ${ }^{1}$ Venkatramana Pegadaraju, ${ }^{2}$ John Reese,${ }^{3}$ and Jyoti Shah ${ }^{1}$ \\ ${ }^{1}$ Department of Biological Sciences, University of North Texas, Denton 76203, U.S.A.; ${ }^{2}$ Division of Biology and ${ }^{3}$ Department \\ of Entomology, Kansas State University, Manhattan 66506, U.S.A.
}

Submitted 26 October 2009. Accepted 7 January 2010.

\begin{abstract}
Myzus persicae, commonly known as green peach aphid (GPA), is a sap-sucking insect with a broad host range. Arabidopsis thaliana responds to GPA infestation with elevated expression of the PHYTOALEXIN DEFICIENT4 (PAD4) gene. Previously, we had demonstrated that the loss of $P A D 4$ gene function compromises Arabidopsis resistance to GPA. In contrast, a mutation in the Arabidopsis SUPPRESSOR OF SALICYLIC ACID INSENSITIVITY2 (SSI2) gene, which encodes a desaturase involved in lipid metabolism, resulted in hyper-resistance to GPA. We demonstrate here that $P A D 4$ is required for the ssi2-dependent heightened resistance to GPA. Based on electrical monitoring of insect behavior and bioassays in which the insect was given a choice between the wild type and the ssi2 mutant, it is concluded that the ssi2-conferred resistance is not due to deterrence of insect settling or feeding from the phloem of the mutant. Instead, hyper-resistance in the ssi 2 mutant results from heightened antibiosis that curtails insect reproduction. Petiole exudates collected from uninfested ssi2 plants contain elevated levels of an activity that interferes with aphid reproduction in synthetic diets. PAD4 was required for the accumulation of this antibiotic activity in petiole exudates, supporting the role of $P A D 4$ in phloembased resistance. Because $P A D 4$ expression is not elevated in the ssi2 mutant, we suggest that basal PAD4 expression contributes to this antibiosis.
\end{abstract}

Aphids are phloem-feeding insects that constrain crop yield due to removal of photoassimilates (Blackman and Eastop 2000). In addition, several aphids also vector plant viruses (Kennedy et al. 1962). The high reproductive capacity of aphids resulting from their ability to reproduce asexually further accentuates their impact as agricultural pests. Aphids utilize their long and slender stylets to penetrate plant tissue, primarily via an intercellular route leading to the sieve elements from which the insect ingests phloem sap. Analyses of exudates collected from excised stylets have confirmed that an aphid's diet represents pure phloem sap (Unwin 1978; Tjallingii and Esch 1993; Zhu et al. 2005).

Host plant acceptance by aphids occurs as a sequence of behaviors at the plant surface and during penetration through host

Corresponding author: Jyoti Shah; Telephone: +1.940.565.3535; Fax: +1.940.565.4136; E-mail: Shah@unt.edu

Current address for V. Pegadaraju: BioDiagonostics, River Falls, WI 54022, U.S.A.

* The $e$-Xtra logo stands for "electronic extra" and indicates that two supplementary tables and one supplementary figure are available online. tissues (Klingauf 1987; Powell et al. 2006). It includes initial assessment of plant topology; sensation of gestation cues by the aphid antennae; probing of the epidermal, mesophyll, and parenchyma cells by the stylet; sieve element puncture and salivation; and, finally, phloem acceptance and sustained ingestion of sap (Powell et al. 2006; Walling 2008). These different behavioral patterns of the aphid have been studied by the electrical penetration graph (EPG) technique in which different patterns of electrical waveforms generated by a wired insect distinguish the activities of the insect (Tjallingii 1988; Walker 2000). Salivary secretions of the aphid facilitate feeding and avert activation of plant defenses. Two major types of saliva are secreted by aphids (Miles 1999). The proteinaceous sheath saliva, which is secreted prior to stylet insertion and thereafter continuously during stylet penetration, envelops the stylet, thereby sealing wounds resulting from penetration and, thus, limiting the activation of wounding associated defenses (Tjallingii 2006). In contrast, the watery saliva, which is secreted continuously during feeding from the sieve elements, contains several proteins that can modulate plant physiology and facilitate feeding and aphid performance on the host (Cherqui and Tjallingii 2000). For example, calcium-binding proteins present in the aphid saliva reverse phloem occlusion triggered by calcium flux in stylet penetrated sieve elements, thus allowing the insect to continuously feed from a sieve element (Will et al. 2007). The importance of salivary proteins to insect performance on the host is also evident from studies in pea aphid, in which RNAi-mediated knockdown of the salivary protein C002 severely impacted aphid settling on the host plant (Mutti et al. 2008).

Plants have evolved multiple strategies to control aphid infestation (Pedigo 1999; Smith 2005; Powell et al. 2006; Goggin 2007; Walling 2008). These can be exerted at various stages of the interaction, contributing to antixenosis, which adversely impacts insect settling and feeding from a plant, and antibiosis, which curtails aphid reproduction. For example, surface features as well as chemicals released from waxes and trichomes on the plant surface can deter insect settling on a plant (Walling 2008), and callose deposition in the sieve elements can interfere with prolonged feeding by aphids (Will et al. 2007). The sieve element is also a route via which antibiotic factors can be delivered to the aphid. Lectins and protease inhibitors that accumulate in the sap have antibiotic effect on aphids (Ribeiro et al. 2006; Sylwia et al. 2006; Wu et al. 2006). The phloem sap also accumulates secondary metabolites such as glucosinolates, which serve as reservoirs for the release of toxic cyanates and nitriles in Brassica spp. (Halkier and Gershenzon 2006). Breakdown products of glucosinolates can also deter aphid feeding (Kim et al. 2008). Antibiosis could also result from absence of sufficient nutrients for the aphid in the host plant (Smith 2005). 
Green peach aphid (GPA) (Myzus persicae Sülzer) is considered to be the most polyphagous of all aphids (Blackman and Eastop 2000), having a host range that spans $>50$ families of plants (Baker 1994; Cabrera y Poch et al. 1998). It is also the most common pest of Arabidopsis thaliana (Bush et al. 2006). The interaction between A. thaliana and the GPA has been utilized in recent years to unravel the molecular and physiological basis of host defense against aphids (de Vos et al. 2007; Goggin 2007). The Arabidopsis PHYTOALEXIN DEFICIENT4 (PAD4) gene, which is an important component of plant disease resistance, was demonstrated to be an important regulator of Arabidopsis defenses against GPA, as well (Pegadaraju et al. 2005, 2007). PAD4 expression was induced in GPA-infested plants (Pegadaraju et al. 2005, 2007; Couldridge et al. 2007). Furthermore, genetic studies with the pad4 mutant and transgenic plants constitutively overexpressing PAD4 indicated that a PAD4-dependent antixenotic activity was required for deterring aphid settling on the host plant and feeding from the sieve elements. In addition, because the GPA population was significantly larger on the pad4 mutant and lower on PAD4 (overexpression) plants than the wild-type (WT) plant, it was suggested that PAD4 also contributes to antibiosis (Pegadaraju et al. 2007). PAD4-conferred resistance to GPA was accompanied by the activation of premature leaf senescence and elevated expression of the SENESCENCE-ASSOCIATED GENES SAG13, SAG21, and SAG27 (Pegadaraju et al. 2005). This observation, in conjunction with the GPA hyper-resistance phenotype of the hyper-senescent suppressor of $S A$ insensitivity2 (ssi2) and constitutive expression of $P R$ genes 5 (cpr5) mutants, led to the suggestion that premature leaf senescence may be a defense mechanism utilized by Arabidopsis to control GPA infestation (Pegadaraju et al. 2005).

The SSI2 gene encodes a plastid-localized fatty acid (FA) desaturase that is involved in the synthesis of oleic acid (18:1) from stearic acid (18:0) (Kachroo et al. 2001). Lipid composition is altered and salicylic acid (SA) content is elevated in the ssi2 mutant, which is a dwarf and exhibits heightened resistance to a number of pathogens (Kachroo et al. 2001; Shah et al. 2001; Sekine et al. 2004). Although elevated SA content was required for the ssi2-conferred heightened resistance to pathogens (Shah et al. 2001; Sekine et al. 2004), studies with the ssi2 nahG plant, which expresses the bacterial nahG-encoded SA-degrading salicylate hydroxylase and, thus, does not accumulate SA at elevated levels, indicated that SA was not essential for the ssi2-conferred hyper-resistance to GPA (Pegadaraju et al. 2005). Experiments with the SA biosynthesis mutant, sid2, and the SAinsensitive nprl mutants confirmed that SA signaling was not required for Arabidopsis defense against GPA (Pegadaraju et al. 2005). Quite to the contrary, it has been suggested that NPRI may repress the timely activation of jasmonic acid signaling and, thus, function as a susceptibility factor in Arabidopsis interaction with GPA (Mewis et al. 2006).

In this study, we demonstrate that PAD4 is required for the ssi2-determined hyper-resistance to GPA, which results from elevated antibiosis activity that can be recovered in phloemsap-enriched petiole exudates. Basal expression of PAD4 is required for the accumulation of this antibiotic activity in petiole exudates from uninfested WT and ssi2 plants, confirming that PAD4 is required for phloem-localized antibiosis, in addition to antixenotic defenses against GPA.

\section{RESULTS}

$P A D 4$ is required for the ssi2-conferred enhanced resistance to the GPA.

Previously, we showed that constitutive overexpression of $P A D 4$ from the Cauliflower mosaic virus $35 \mathrm{~S}$ promoter en- hanced GPA resistance in Arabidopsis (Pegadaraju et al. 2007). To determine whether ssi2-conferred enhanced resistance was accompanied by constitutive overexpression of $P A D 4$, reversetranscription polymerase chain reaction (RT-PCR) was used to compare $P A D 4$ transcript level in leaves of the uninfested ssi2 mutant and the WT plant. Expression of the actin ACT8 gene provided the control for RT-PCR. Compared with the WT, PAD4 expression was not elevated in leaves of the ssi2 mutant (Fig. 1A), suggesting that ssi2-conferred resistance is not due to constitutive overexpression of $P A D 4$. Furthermore, the temporal pattern of induction of PAD4 expression in response to GPA infestation was comparable between the WT and the ssi2 mutant plant.

To establish whether PAD4 is required for the ssi2-conferred heightened resistance, a no-choice bioassay was performed with the ssi 2 pad4 double mutant plant. Twenty GPA were released on each ssi2 and pad4 single mutant and the ssi2 pad4 double mutant plant. The WT plants served as the control. Aphid numbers on each plant were determined $48 \mathrm{~h}$ later. In F3 progeny of two independent ssi2 pad4 double mutant lines, presence of the pad4 mutant allele attenuated the ssi2-conferred enhanced GPA resistance (Fig. 1B). Aphid numbers on ssi2 pad4 line no. 2 were comparable with that on the pad4 single mutant in accession Columbia $(\mathrm{Col})$, while aphid numbers on line no. 4 were comparable to that on the WT accession $\mathrm{Col}$ and Nössen (Nö). Because the recessive pad4 and $s s i 2$ alleles are in the Col and Nö accessions, respectively, GPA numbers were also determined on individual plants of a segregating F2 population derived from a ssi2/+ pad4/+ hybrid F1 plant (Fig. 1C; Supplementary Table 1). As expected, the ssi2 and pad4 mutant alleles segregated as recessive alleles in this population. Plant-to-plant variations in insect numbers were observed for all genotypes (Fig. 1C). However, for plants of each genotype, the variations in insect numbers were in a small range. Insect numbers on all F2 plants that contained at least one copy of the WT PAD4 and SSI2 allele were within the range of insect numbers observed on WT accession Col and Nö plants.

Transgressive segregation for aphid resistance was not observed in the F2 population. In contrast to the WT plants, insect numbers on F2 progeny homozygous for the pad4 allele and containing at least one copy of the SSI2 allele were within the range of insect numbers on the pad4 mutant in accession Col. In addition, comparably low insect numbers were observed on the ssi2 mutant in the accession Nö and F2 progeny that were homozygous for the ssi2 allele and contained at least one copy of the WT PAD4 allele. However, in F2 segregants that were doubly homozygous for the ssi2 and pad4 alleles, insect numbers were within the range of insect numbers observed on the pad4 single mutant in accession Col. Taken together, these results confirm that $P A D 4$ is the major locus required for the ssi2-determined heightened GPA resistance. However, considering the small size of the F2 population evaluated in this study (Fig. 1C), this data does not rule out the possibility that other minor loci can influence the interaction between the ssi2 and pad4 alleles. Quite to the contrary, the fact that, unlike ssi2 pad4 line no. 2, aphid numbers on ssi2 pad4 line no. 4 were comparable with numbers on the WT, suggests that other loci do modulate the impact of the ssi2 and pad4 alleles on aphid performance.

\section{$P A D 4$ is required for the $s s i 2$-determined} constitutive overexpression of SAG13, SAG21, and SAG27.

Compared with the WT plant, SAG13, SAG21, and SAG27 transcript levels were constitutively elevated in leaves of the ssi 2 mutant (Pegadaraju et al. 2005). PAD4 modulates the GPA feeding-induced accumulation of these $S A G$ transcripts in 
Arabidopsis leaves (Pegadaraju et al. 2005). To test the role of $P A D 4$ in ssi2-conferred constitutive expression of $S A G$ genes, $S A G 13, S A G 21$, and $S A G 27$ expression was characterized in the ssi2 pad4 double-mutant lines no. 2 and 4 and the ssi 2 and pad4 single-mutant plants. WT Col and Nö plants were used as controls. Compared with the ssi2 single mutant, constitutive overexpression of $S A G 13, S A G 21$, and $S A G 27$ was not observed in the uninfested ssi2 pad4 double mutant lines (Fig. 2), indicating that $P A D 4$ is required for the ssi2-determined constitutive overexpression of $S A G 13, S A G 21$, and $S A G 27$. The temporal pattern of induction of $S A G 13, S A G 21$, and $S A G 27$ expression in response to GPA infestation varied between the two ssi 2 pad4 double-mutant lines; it was comparable with the WT in ssi2 pad4 line no. 4 and intermediate to the WT and pad4 single mutant in line no. 2 . These results confirm our previous observation (Pegadaraju et al. 2005, 2007) that mutations in $P A D 4$ do not abolish $S A G$ gene expression but, rather, affect the temporal pattern of $S A G$ gene expression in GPA-infested plants.

\section{GPA settling and feeding are unaffected} on the ssi2 mutant.

The ssi2 mutant is a dwarf with crinkled leaves (Shah et al. 2001). The surface alterations in ssi2 could deter insect movement, settling, and feeding on the mutant plant. A choice assay in which GPA was given the option of settling on the WT or the ssi 2 mutant plant was conducted to determine whether insect settling is deterred on the ssi2 mutant. Twenty adult apter-
A
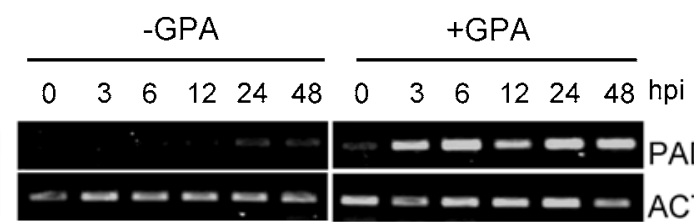

WT (Nö)

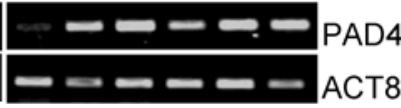
ssi2
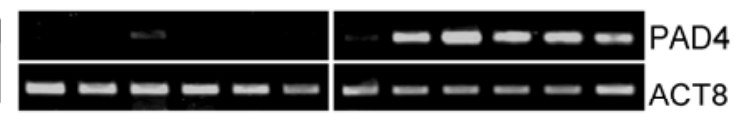<smiles></smiles>
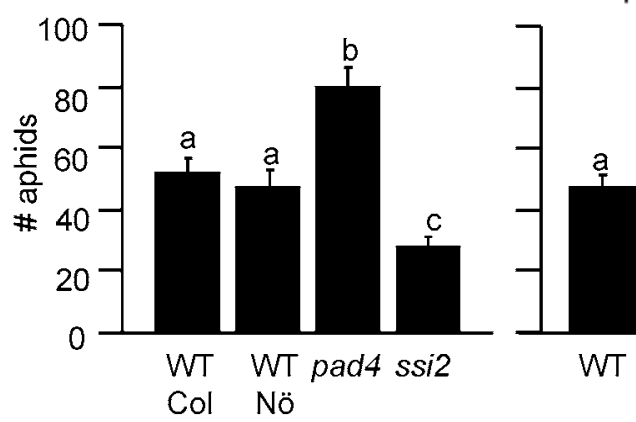

$F_{2}$ segregating

population

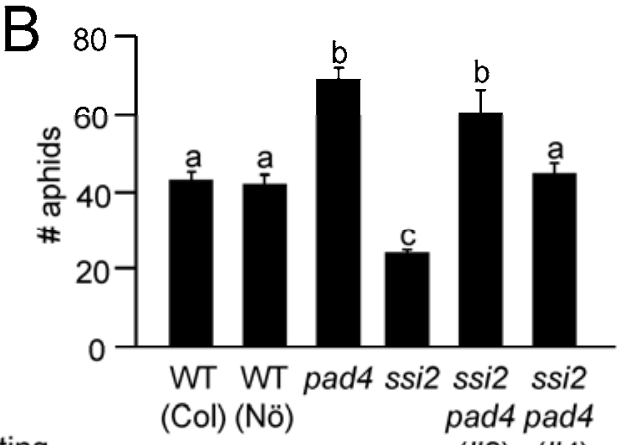

(Col) (Nö)

(\#2) (\#4)
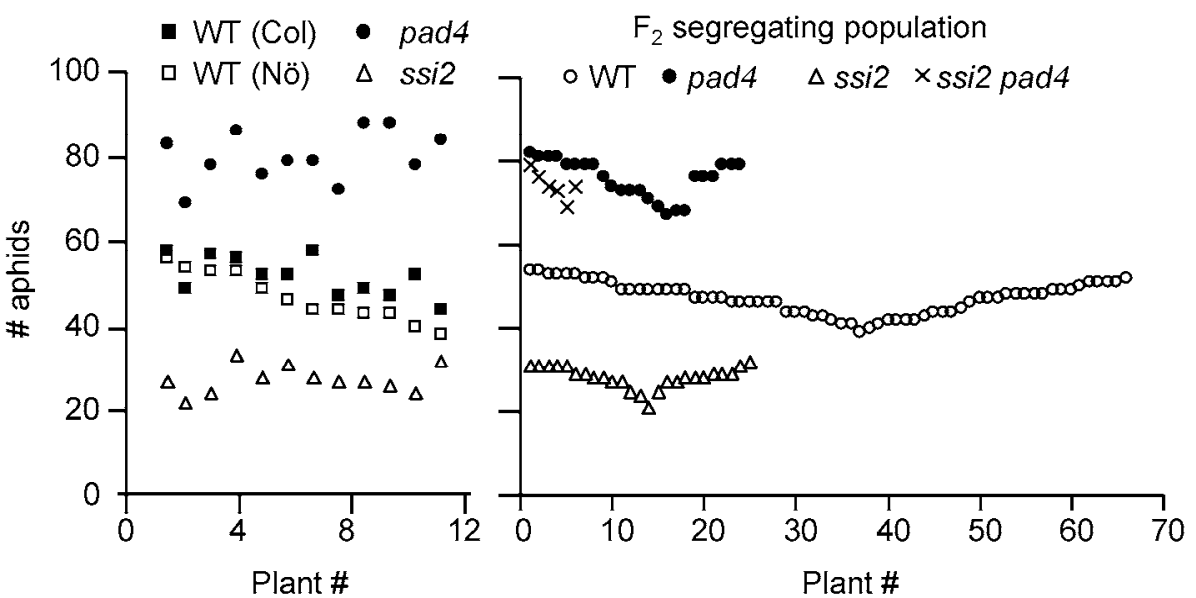

Fig. 1. PHYTOALEXIN DEFICIENT4 (PAD4) is required for the suppressor of salicylic acid insensitivity2 (ssi2)-determined hyper-resistance to green peach aphid (GPA). A, Reverse-transcription polymerase chain reaction (RT-PCR) analysis of PAD4 expression in uninfested (-GPA) and GPA-infested (+GPA) leaves of the wild-type (WT) accession Nö and the ssi2 mutant plant. RNA for RT-PCR analysis was harvested at the indicated hours postinfestation (hpi). Expression of the ACT8 gene served as a control for RNA quality and RT-PCR. B, No-choice assay: Comparison of GPA numbers on WT accession Col and Nö, the pad4 and ssi2 mutant, and two independently derived lines of the ssi2 pad4 double-mutant plants. All values are mean from a minimum of 12 plants \pm standard error (SE). C, No-choice assay: Comparison of GPA numbers on F2 progeny derived from a ssi2/+ pad4/+ F1 hybrid. WT accession Col and Nö, and pad4 (in accession $\mathrm{Col}$ ) and ssi2 (in accession Nö) mutant plants were used as controls. Top panels: average count of aphids \pm SE per plant. Lower panel: GPA numbers on individual plants of the indicated genotypes. In B and C, 20 aphids were released on each plant. The total number of aphids (adults + nymphs) on each plant was determined at 2 days postinfestation. Analysis of variance of GPA populations on different plant genotypes were conducted using PROC GLM (SAS Institute). Means, when significant, were separated using least significant difference procedure. Different letters above the bars indicate values that are significantly different $(P<0.05)$ from each other. Experiments in A and B were repeated thrice. 
ous (wingless) GPA were released at the center of each pot containing a WT and an ssi 2 mutant plant. The number of insects that had settled on each plant genotype was monitored over a 24-h period. The average number of GPA that had settled on the WT and the ssi2 mutant was comparable over the 24-h period (Fig. 3), suggesting that the ssi2-conferred hyperresistance is not due to factors that deter insect settling on the mutant plant.

The EPG technique was used to compare insect feeding behavior on the WT and the ssi2 mutant plant. EPG permits realtime monitoring of aphid feeding behavior on the host plant (Walker 2000). Representative EPG waveforms produced by GPA probing on leaves of WT Arabidopsis are shown in Figure 4A. Parameters measured include the time to first probe

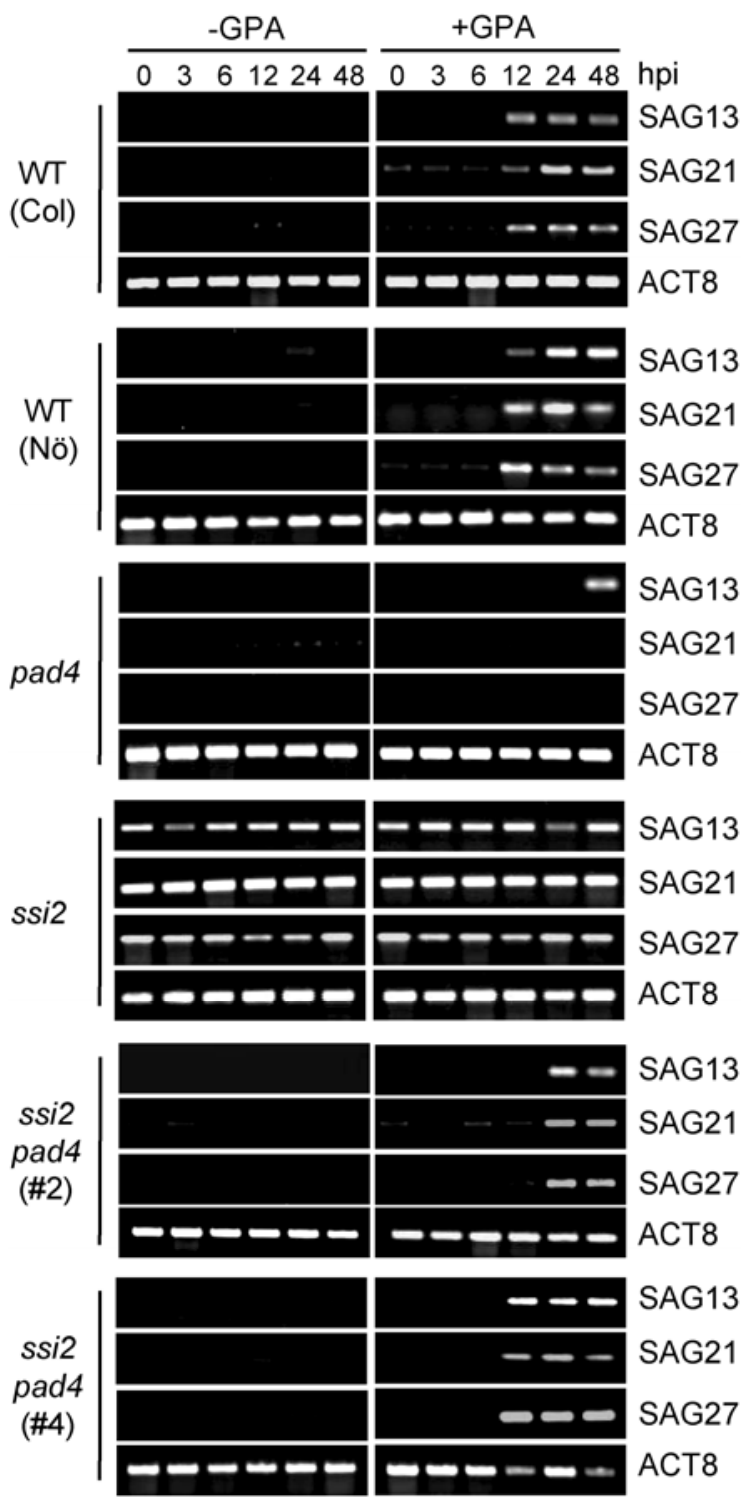

Fig. 2. PHYTOALEXIN DEFICIENT4 (PAD4) is required for the suppressor of salicylic acid insensitivity2 (ssi2)-determined constitutive expression of $S A G 13, S A G 21$, and $S A G 27$. Reverse-transcription polymerase chain reaction (RT-PCR) analysis of SAG13, SAG21, and SAG27 expression in uninfested (-green peach aphid [GPA]) and GPA-infested (+GPA) leaves of the wild-type (WT) accession $\mathrm{Col}$ and $\mathrm{Nö}$, the pad4 and ssi 2 mutant, and two independently derived lines of the ssi 2 pad4 double-mutant plants. RNA for RT-PCR analysis was harvested at the indicated hours postinfestation (hpi). Expression of the ACT8 gene served as a control for RNA quality and RT-PCR. This experiment was repeated thrice.
(FP), total duration of nonprobing phase (NP), time to reach first sieve element phase (f-SEP), sum of SEP duration in a total of $8 \mathrm{~h}$ of recording time (s-SEP), available SEP (a-SEP) from the beginning of the first SEP until the end of the recording, the percentage of available SEP actually spent in SEP $(\% \mathrm{SEP})$, the amount of time spent drinking from xylem (xylem phase $[\mathrm{XP}]$ ), and total duration of pathway phase (PP) when the insect is not feeding from the xylem or the sieve elements and the NP (Fig. 4B; Table 1). There were no significant differences in any of these parameters measured for GPA behavior on the WT and the ssi2 mutant $(P>0.05)$, suggesting that aphid feeding behavior was unaffected on the ssi2 mutant plant. Taken together, the choice assay and EPG results indicate that heightened GPA resistance in the ssi2 mutant is not due to enhanced antixenotic activity.

\section{Elevated antibiosis activity contributes} to ssi2-dependent hyper-resistance to the GPA.

Petiole exudates, which are enriched in phloem sap, collected from uninfested Arabidopsis leaves contain an antibiosis activity that adversely affects GPA reproduction when added to a synthetic diet. Compared with the synthetic diet (diet alone) or diet containing the buffer that was used to collect petiole exudates, population size of GPA was significantly lower when reared for 4 days on diet supplemented with petiole exudates collected from WT accession $\mathrm{Col}$ and Nö leaves (Fig. 5). A further reduction in population size was observed when GPA was reared on diet supplemented with petiole exudates collected from leaves of the ssi2 mutant. These results indicate that an elevated level of an antibiosis factor in the petiole exudate contributes to ssi2-determined heightened resistance to the GPA.

GPA population was larger on diet supplemented with petiole exudates collected from the two ssi2 pad4 double mutant lines than the ssi 2 single mutant (Fig. 5), confirming that $P A D 4$ is required for the elevated accumulation of antibiosis activity in ssi2 petiole exudate. Figure 5 also indicates that petiole exudate collected from the pad4 mutant lacks antibiosis activity. Petiole exudates used in the above experiments were collected from uninfested plants, and PAD4 is not constitutively overexpressed in the ssi 2 mutant; therefore, we suggest that basal level of the PAD4 transcript is required for the accumulation of an antibiosis factor in petiole exudates of the WT and the ssi 2 mutant. The absence of enhanced antibiosis activity in

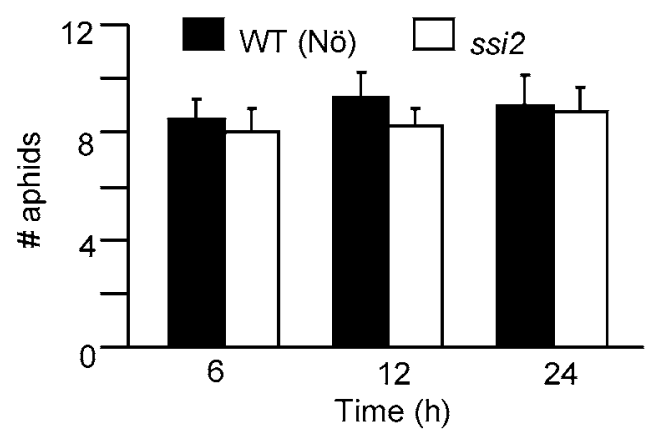

Fig. 3. Choice test comparison of green peach aphid (GPA) preference for wild-type (WT) versus the suppressor of salicylic acid insensitivity2 (ssi2) mutant plant. Twenty adult apterous aphids were released at the center of a pot containing one WT accession Nö and one ssi2 plant, equidistant from the two plants. The number of adult GPA that had settled on each plant was determined 6,12 , and $24 \mathrm{~h}$ after release. Values are the average \pm standard error of aphid counts on a minimum of eight plants of each genotype for each time point. Means were separated using paired $t$ test $(P$ $<0.05)$. At none of the time points were statistically significant differences observed between insect numbers on the WT and the ssi2 mutant. This experiment was replicated thrice. 
petiole exudate of a transgenic line constitutively overexpressing the PAD4 transcript from the Cauliflower mosaic virus $35 \mathrm{~S}$ promoter (Supplementary Fig. 1) supports this hypothesis.

\section{ssi2-conferred hyper-resistance does not result}

\section{from a direct impact of stearic acid on GPA fecundity.}

Compared with the WT, leaves of the ssi2 mutant contain 10-fold higher levels of stearic acid (Kachroo et al. 2001). To determine whether the reduced fecundity on the ssi 2 mutant was a direct result of increased consumption of stearic acid by GPA, GPA were reared for 4 days on synthetic diet supplemented with stearic acid (18:0). GPA reared on diet alone, diet containing methanol that was used as a solvent for the FA, and on diet supplemented with oleic acid (18:1) provided the negative controls. Presence of 18:0 and 18:1 in the synthetic diet did not adversely affect the GPA population (Fig. 6A). Furthermore, infiltration of 18:0 and 18:1 into leaves of WT Arabidopsis did not curtail GPA fecundity (Fig. 6B), supporting the conclusion that the heightened antibiosis activity in the ssi2 mutant plant is not due to a direct antibiosis effect of 18:0.
SA and an additional factor contribute to the antibiosis activity in ssi2 petiole exudate.

Compared with the WT, leaves of the ssi 2 mutant constitutively accumulate sevenfold higher levels of SA (Shah et al. 2001), which is equivalent to an in planta concentration of approximately $15 \mu \mathrm{M}$. Similarly, SA-glucoside (SAG) content of the ssi2 leaf, which is equivalent to approximately $210 \mu \mathrm{M}$ SA, represents a 100-fold increase over SAG content in WT leaves. Furthermore, SA included in a synthetic diet at 10 and $25 \mu \mathrm{M}$ resulted in 30 and $60 \%$ reduction, respectively, in GPA numbers, compared with diet lacking SA (Fig. 7A). This result suggests that SA at elevated levels can adversely impact GPA reproduction. To determine SA's contribution to the antibiosis activity present in ssi2 petiole exudate, feeding trials were conducted with petiole exudate collected from the ssi2 nahG plant in which, unlike the ssi2 single mutant, SA content was not elevated (Shah et al. 2001). The synthetic diet, diet containing the buffer used to collect petiole exudates, and petiole exudate collected from WT accession Nö plant provided the controls. Presence of $n a h G$ in the ssi2 $n a h G$ plant only partially attenu-

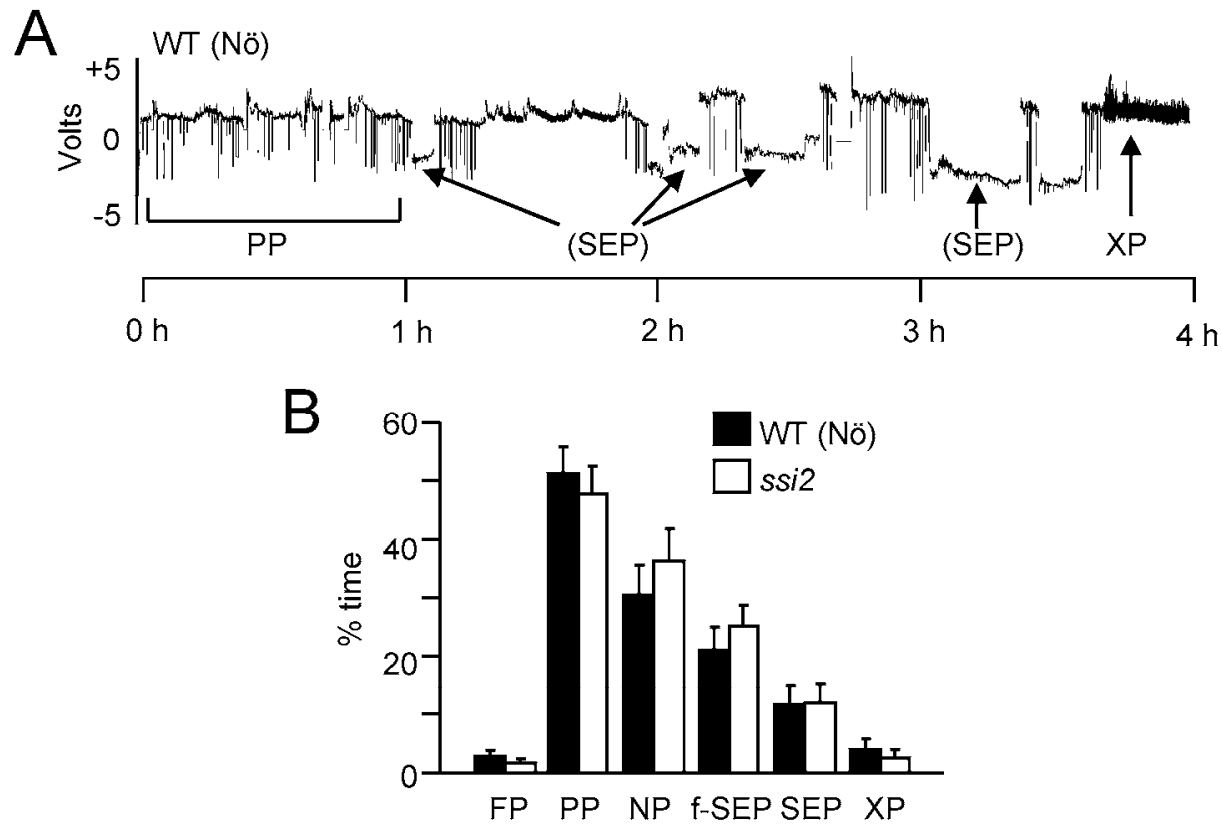

Fig. 4. Electrical penetration graph analysis of green peach aphid (GPA) behavior on Arabidopsis. A, Representative waveform patterns over a 4-h period of a GPA feeding on a leaf of a wild-type (WT) Arabidopsis accession Nö plant. The plant and insect were held inside a Faraday cage during the recording at an ambient temperature of approximately $22^{\circ} \mathrm{C}$. The different patterns represent different phases of aphid probing of the plant. The pathway phase (PP) represents the probing of intercellular spaces by the stylet. The sieve element phase (SEP) and xylem phase (XP) represent the phase when the stylet is inserted into a sieve element and a xylem, respectively. B, Percentage of time spent by GPA for various activities on WT (Nö) and suppressor of salicylic acid insensitivity 2 (ssi2) plants in $8 \mathrm{~h}$ of recording time. Each value is the average \pm standard error of 20 replications. The percent time spent by GPA on various activities was analyzed by the nonparametric Kruskal-Wallis test $(P<0.05)$. Statistically significant differences were not observed for any of the parameters between insect feeding on the WT and the ssi2 mutant.

Table 1. Mean time (h) \pm standard error (SE) spent by green peach aphids (GPA) for various activities on Arabidopsis wild-type (WT Nö) and suppressor of salicylic acid insensitivity 2 (ssi2) mutant plants in $8 \mathrm{~h}$ of recording

\begin{tabular}{|c|c|c|}
\hline Parameters & WT $(\mathbf{N o ̈})^{\mathbf{a}}$ & $s s i 2^{b}$ \\
\hline Time to first probe (FP) & $0.22 \pm 0.08$ & $0.13 \pm 0.06$ \\
\hline Total duration of pathway phase (PP) & $4.10 \pm 0.36$ & $3.83 \pm 0.37$ \\
\hline Total duration of nonprobing phase (NP) & $2.65 \pm 0.41$ & $2.89 \pm 0.46$ \\
\hline Time to first Sieve Element Phase (f-SEP) & $1.68 \pm 0.50$ & $2.00 \pm 0.51$ \\
\hline Sum of SEP duration time in a total of $8 \mathrm{~h}$ of recording time (s-SEP) & $0.93 \pm 0.27$ & $0.95 \pm 0.27$ \\
\hline Total duration of xylem phase (XP) & $0.32 \pm 0.42$ & $0.33 \pm 0.44$ \\
\hline Available SEP from the beginning of the first SEP until the end of recording time (a-SEP) & $6.32 \pm 0.65$ & $6.00 \pm 0.68$ \\
\hline Percentage of available SEP actually spent in SEP (\%SEP) & $22.57 \pm 0.07$ & $20.94 \pm 0.06$ \\
\hline
\end{tabular}

\footnotetext{
${ }^{\text {a }}$ Each value is the average \pm SE of 20 replications.

${ }^{\mathrm{b}}$ None of the parameters were significantly different when GPA were on the WT and the ssi2 mutant $(P<0.05$, Kruskal-Wallis test).
} 
ated the ssi2-dependent antibiosis activity (Fig 7B), suggesting that SA and an additional unknown factor present in the petiole exudate of the ssi2 mutant contribute to antibiosis. However, because ssi2-conferred hyper-resistance and constitutive $S A G 13$ expression are retained in the ssi2 nahG plant (Pegadaraju et al. 2005) we suggest that in planta SA's toxic effect on GPA is not a major contributor to the ssi2-conferred hyper-resistance.

\section{DISCUSSION}

Resistant plants counter aphids by adopting a variety of defense strategies that impair the ability of the insect to select and settle, feed, develop, and reproduce on the plant (Pedigo 1999). Choice assays in which GPA was given the option between the WT and ssi2 mutant plants indicated that plant choice by GPA and insect settling were not adversely affected on the ssi2 mutant (Fig. 3). Furthermore, no irregularities in GPA behavior and feeding ability were observed by EPG analysis on the ssi2 mutant (Fig. 4B; Table 1). Based on these results, we conclude that the ssi2-conferred hyper-resistance is not due to heightened antixenosis activity. Instead, we propose that the ssi2-conferred hyper-resistance is as a result of increased antibiosis activity in the mutant compared with the WT plant.

EPG analysis did not uncover significant differences in the FP, f-SEP, and durations of the PP and NP when GPA was feeding on the ssi 2 mutant compared with the WT plant, suggesting that the ssi2-mediated antibiosis is unlikely to be exerted at the surface or during stages outside of the SEP. Antibiosis can result from poor availability in the phloem sap of nutrients required by the aphid or due to presence of a metabolite that adversely impacts insect reproduction (Pedigo 1999; Smith 2005). Feeding trials on synthetic diet indicate that inclusion of petiole exudate collected from ssi2 plants in the synthetic diet curtailed aphid reproduction (Fig. 5), suggesting that ssi2-conferred antibiosis is unlikely due to nutrient defi-

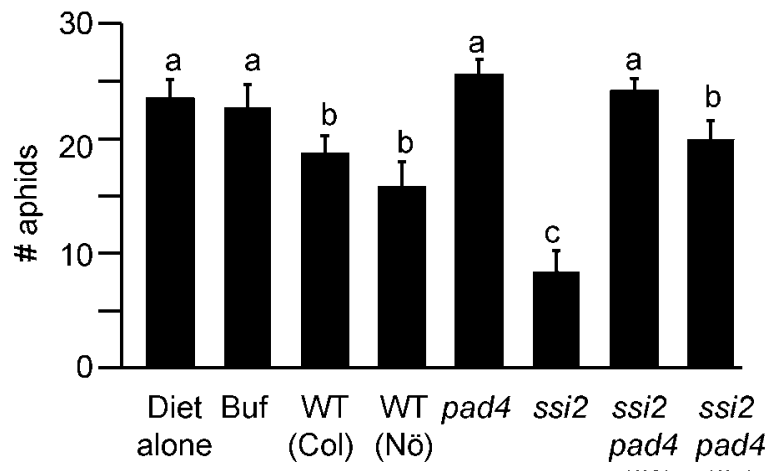

(\#2) (\#4)

Fig. 5. Suppressor of salicylic acid insensitivity2 (ssi2) petiole exudate contains elevated levels of a PHYTOALEXIN DEFICIENT4 (PAD4)-dependent antibiotic activity. Comparison of green peach aphid (GPA) numbers on synthetic diet, synthetic diet containing the buffer used to collect petiole exudates, and synthetic diet containing petiole exudates from wildtype (WT) accession Col and Nö plants, and the pad4, ssi2, and the two ssi2 pad4 double-mutant lines (nos. 2 and 4). Three adult apterous aphids were introduced into each feeding chamber and allowed to feed on the exudates mixed with the synthetic diet. The total numbers of aphids (adults + nymphs) in each feeding chamber were determined 4 days later. Each experiment contained three replicates for each treatment. All values are average \pm standard error of aphids (adults + nymphs) per feeding chamber. Analysis of variance of GPA populations on different plant petiole exudates was conducted using PROC GLM (SAS Institute). Means, when significant, were separated using least significant difference procedure. Different letters above the bars indicate values that are significantly different $(P<0.05)$ from each other. This experiment was replicated thrice. ciency but, instead, is due to presence of a factor or factors that adversely affect insect reproduction. Because petiole exudate from the ssi2 mutant was more effective in curtailing GPA reproduction than petiole exudate from the WT plant, we suggest that the ssi2 petiole exudate contains elevated levels of a factor that curtails GPA reproduction. Furthermore, because aphids consume large amounts of phloem sap from the sieve elements of the host plant and petiole exudate is enriched in phloem sap, we suggest that GPA comes in contact with this antibiosis factor when it taps into the sieve elements.

Lack of the SSI2-encoded desaturase activity results in the accumulation of stearic acid in the ssi2 mutant plant (Kachroo et al. 2001; Nandi et al. 2003). However, feeding trials in which stearic acid was included in the synthetic diet indicated that presence of stearic acid in the diet did not curtail GPA reproduction (Fig. 6A). Infiltration of stearic acid into leaves of
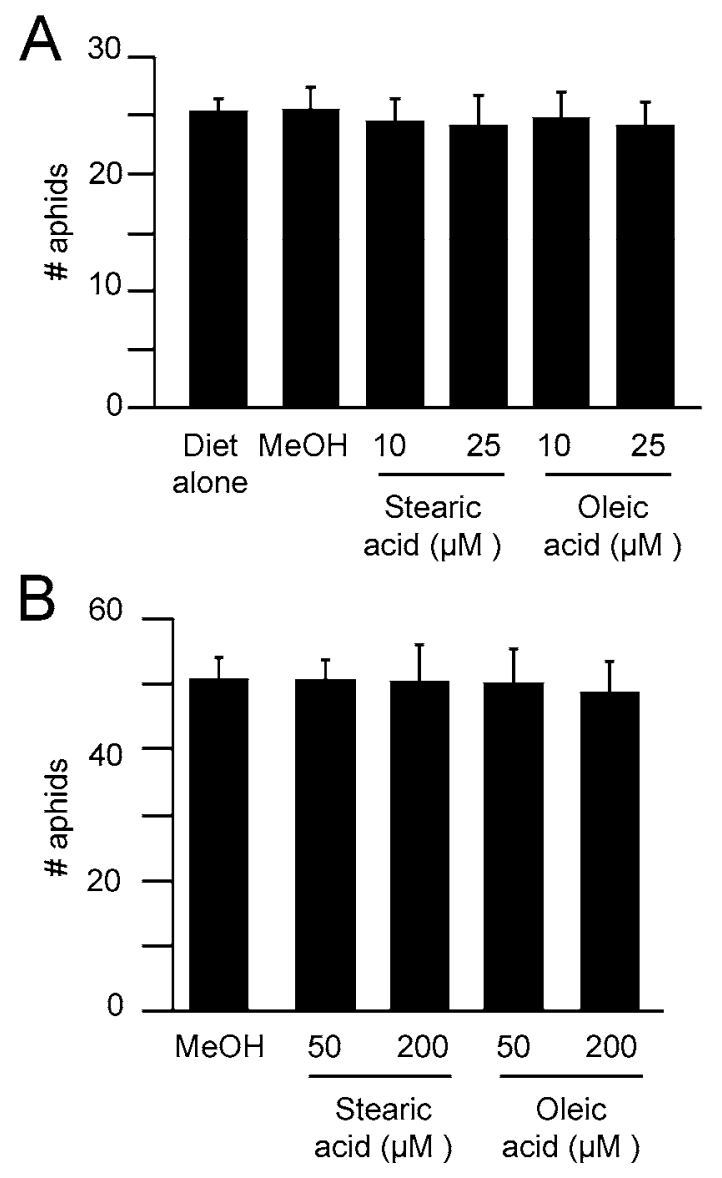

Fig. 6. Effect of fatty acids on aphid population size. A, Comparison of green peach aphid (GPA) numbers on synthetic diet supplemented with different concentrations of stearic acid and oleic acid. Diet alone and diet supplemented with methanol $(\mathrm{MeOH})$, which was used as a solvent for the fatty acids, provided the negative controls. Three adult aphids were introduced into each feeding chamber and allowed to feed on the diet. The total number of aphids (adults + nymphs) in each feeding chamber was determined 4 days later. Values are means \pm standard error (SE) of three replicates for each treatment. Analysis of variance (ANOVA) of GPA populations on different treatments was conducted using PROC GLM (SAS Institute). The experiment was replicated twice. B, No-choice assay: comparison of GPA numbers on wild-type (WT) accession Col plants infiltrated with different concentrations of stearic and oleic acid and, as a negative control, with $\mathrm{MeOH}$. Twenty aphids were released on each plant. The total numbers of aphids (adults + nymphs) on each plant were determined at 2 days postinfestation. All values are mean from a minimum of 12 plants \pm SE. ANOVA of GPA populations on different plant genotypes were conducted using PROC GLM (SAS Institute). This experiment was repeated twice. In $\mathrm{A}$ and $\mathrm{B}$, none of the treatments yielded aphid counts that were significantly different from each other at $P<0.05$. 
the WT plant also did not curtail GPA reproduction (Fig. 6B). Together, these results suggest that elevated stearate content of the ssi2 mutant is unlikely to directly contribute to antibiosis against GPA. Instead, the impact of the ssi2 allele on antibiosis could result from the lower oleic acid content in the mutant plant, which may influence defense signaling, leading to enhanced antibiosis. It has been suggested that the ratio of glycerol-3-phosphate to oleic acid is a factor that modulates plant defenses against pathogens (Kachroo et al. 2004). Oleic acid also has been shown to bind and modulate activity of a phospholipase involved in signaling associated with plant stress response (Wang and Wang 2001). Indeed, defense signaling is altered in the ssi2 mutant (Shah et al. 2001) and this may result in the hyperaccumulation of an antibiotic factor in the ssi2 petiole exudate.

Several studies have suggested an important role for phenols in plant defense against aphids. For example, accumulation of phenolic metabolites has been correlated with resistance to the bird cherry-oat aphid (Rhopalosiphum padi) and the cowpea aphid (Aphis craccivora Koch) in resistant cultivars of wheat (Triticum aestivum) and cowpea (Vigna unguiculata L. Walp.)
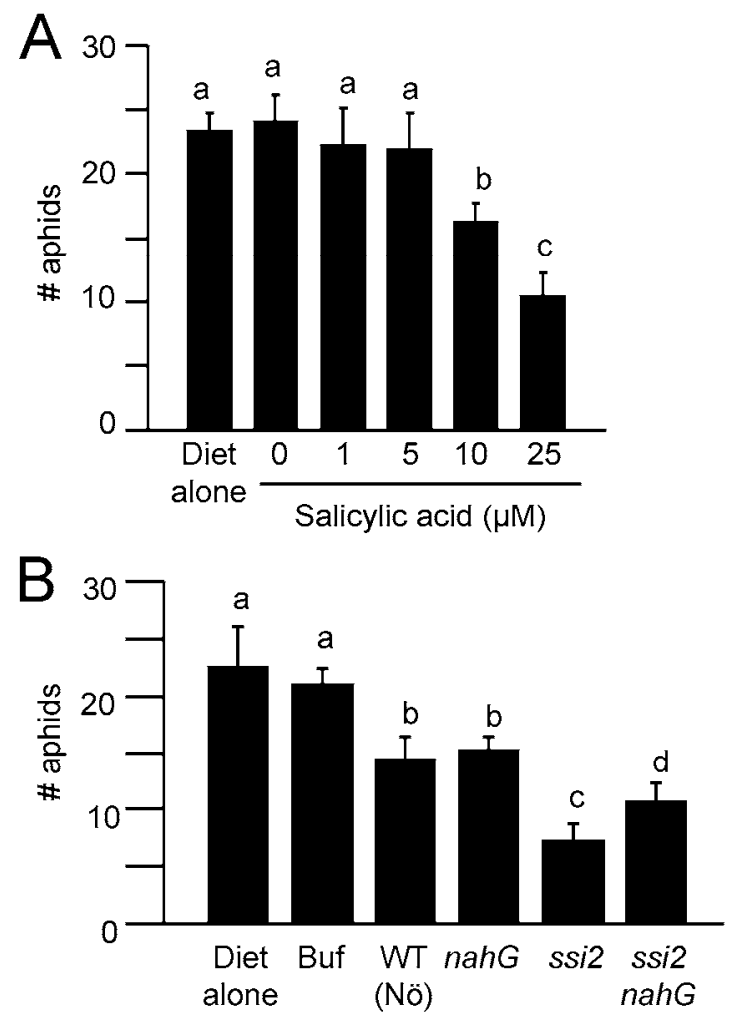

Fig. 7. Effect of salicylic acid on aphid population size. A, Comparison of green peach aphid (GPA) numbers on synthetic diet supplemented with different concentrations of salicylic acid. Diet alone provided the negative controls. Three adult aphids were introduced into each feeding chamber and allowed to feed on the diet. The total numbers of aphids (adults + nymphs) in each chamber was determined 4 days later. B, Comparison of GPA numbers on synthetic diet, diet supplemented with buffer used to collect petiole exudates, and diet supplemented with petiole exudates collected from wild-type (WT)-Nö, nahG, suppressor of salicylic acid insensitivity2 (ssi2), and ssi2 nahG plants. Three adult aphids were introduced into each feeding chamber and allowed to feed on the diet. The total numbers of aphids (adult + nymphs) in each chamber was determined 4 days later. The experiment was replicated thrice. In A and B, all values are means \pm standard error of three replicates for each treatment. Analysis of variance of GPA populations on different plant petiole exudates was conducted using PROC GLM (SAS Institute). Means, when significant, were separated using least significant difference procedure $(P<0.05)$. Different letters above the bars indicate values that are significantly different $(P<0.05)$ from each other.
(Lattanzio et al. 2000; Smith and Boyko 2007). In addition, phenolic flavonoids collected from cowpea, when applied to leaves of faba bean (Vicia faba), curtailed reproduction of the black bean aphid, A. fabae (Scopoli) (Lattanzio et al. 2000). In sorghum, in response to feeding by greenbug (Schizaphis graminum Rodani), expression of a gene encoding a polyphenol oxidase (PPO), which facilitates dimerization of phenolic compounds, was downregulated (Park et al. 2005). In contrast, the sheath and watery saliva of aphids contain PPO, which act on a range of phenolic compounds that occur naturally in plants, suggesting that aphids may utilize PPO to detoxify phenolics in the host plant (Urbanska et al. 1998). SA is also a phenolic compound. SA added to an synthetic diet at concentrations comparable with that in ssi2 leaves adversely impacted GPA reproduction (Fig. 7A), suggesting that SA at levels present in leaves of the ssi2 mutant does have an antibiosis effect on GPA. However, because aphid diet is phloem sap and the concentration of SA in Arabidopsis phloem sap is not known, the antibiotic effect of SA added to the synthetic diet should be treated with caution. Indeed, feeding trials on synthetic diet supplemented with petiole exudate collected from the ssi2 $n a h G$ plant, which lacks the ssi2-determined high SA content (Shah et al. 2001), indicated that SA or a product thereof at best partly contributes to the elevated antibiotic activity in ssi2 petiole exudate (Fig. 7B). Furthermore, we had previously demonstrated that, in no-choice assays, the presence of $n a h G$ did not attenuate the ssi2-conferred resistance to GPA in the ssi2 nahG plant (Pegadaraju et al. 2005). Thus, in planta SA may not be the major contributor to the ssi2-conferred antibiosis. Because petiole exudates from ssi2 nahG leaves contained higher antibiosis activity than petiole exudates from the WT and the $n a h G$ plant, we suggest that the ssi2 petiole exudate contains an additional unknown factor that contributes to antibiosis. Although it is plausible that catechol, a phenolic produced as a result of the $n a h G$-encoded salicylate hydroxylase action on SA, could impact antibiosis, this is less likely considering the results of Kim and Jander (2007), who observed no significant effect of catechol added to synthetic diet on GPA reproduction.

Arabidopsis, like other members of Brassicaceae, contains glucosinolates, which accumulate in the vasculature, and are taken up by GPA when feeding on Arabidopsis (Kim and Jander 2007). Amongst the glucosinolates, 4-methoxyindol-3ylmethylglucosinolate (4MI3M), when added to synthetic diets, was found to be detrimental to GPA (Kim and Jander 2007). It is possible that $4 \mathrm{MI} 3 \mathrm{M}$ or another glucosinolate is responsible for the antibiosis activity present in WT petiole exudates (Figs. 5 and 7B). 4MI3M levels were reported to be higher in Arabidopsis treated with SA analogs and in the cprl and mpk4 mutants which, like ssi2, have a high SA content (Kliebenstein et al. 2002; Mikkelsen et al. 2003, 2004). Whether elevated SA content contributes to the ssi2-determined antibiosis by stimulating 4MI3M accumulation is not known. However, considering that the pad4 mutation, which suppresses the ssi2-conferred antibiosis and resistance to GPA (Figs. 1B and C and 5), was previously shown to have WT levels of 4MI3M and other indole glucosinolates (Kim and Jander 2007), this possibility seems less likely.

Considering that SSI2 is involved in lipid metabolism, it is plausible that a lipid-derived factor is responsible for the heightened antibiotic activity in the ssi2 mutant. MPL1 (At5g14180), which encodes a lipase, was identified as a gene that is expressed at elevated levels in GPA-infested Arabidopsis (Pegadaraju 2005), and mutations in $m p l l$ result in reduced antibiosis to GPA (J. Louis, V. Singh, K. L. Kukula, and J. Shah, unpublished). Because MPL1 is constitutively overexpressed in the ssi2 mutant (J. Louis, V. Singh, K. L. Kukula, 
and J. Shah, unpublished), it is likely that this MPL1-derived lipid product contributes to the elevated antibiotic activity present in petiole exudate of the ssi2 mutant.

Feeding trial experiments presented here (Fig. 5) indicate that $P A D 4$ is required for antibiosis, in addition to the previously demonstrated antixenotic activity (Pegadaraju et al. 2005, 2007). We have demonstrated that PAD4 is required for the ssi2-conferred resistance and for accumulation of the antibiotic activity in ssi2 petiole exudate (Fig. 5). PAD4 transcript accumulation in GPA-infested and uninfested plants was not impacted by the presence of the ssi2 mutation (Fig. 1A), suggesting that, in the ssi2 mutant background, the PAD4-modulated arm contributing to antibiosis is stimulated at a step downstream of PAD4 transcript accumulation (Fig. 8). The ssi2 mutation could result in the accumulation of a hyperactive PAD4 protein. However, in this scenario, because PAD4-dependent antixenosis is not enhanced in the ssi 2 mutant, it is anticipated that the PAD4 protein has a domain that contributes to the antibiosis pathway but not the antixenosis pathway, and it is the activity of this domain that is hyperactive in the ssi 2 mutant. A third possibility is that PAD4 and the ssi2-determined antibiosis result from two parallel mechanisms. However, considering that, in the ssi2 pad4 double mutant line no. 2, the ssi2-determined resistance and antibiosis activity was comparable with that in the pad4 single mutant (Figs. 1B and 5), this third possibility seems the least likely. In the future, identification of the metabolite that contributes to the ssi2-determined antibiosis will help address these alternative hypotheses.

Petiole exudates from uninfested WT plants contain the PAD4-determined antibiosis activity (Fig. 5), suggesting that basal PAD4 expression contributes to the accumulation of this antibiosis activity in petiole exudates. Further support for this hypothesis is obtained from the observation that transgenic plants constitutively overexpressing PAD4 from the Cauliflower mosaic virus $35 \mathrm{~S}$ promoter do not accumulate elevated antibiosis activity. However, previously, we had demonstrated that constitutive overexpression of PAD4 resulted in heightened antixenosis (Pegadaraju et al. 2007). Therefore, we hypothesize that, although the GPA infestation-induced expression of $P A D 4$ contributes to the antixenosis observed in WT Arabidopsis, basal PAD4 expression is sufficient for the accumulation of the antibiotic activity in petiole exudates of the WT and ssi2 mutant plants. Increasing PAD4 transcript abundance beyond this point does not increase the antibiotic activity, presumably because another step or factor (for example, availability of a precursor metabolite or factor) may be rate-limiting.

\section{MATERIALS AND METHODS}

\section{Insects and plants.}

GPA were reared at $22^{\circ} \mathrm{C}$ in a growth chamber programmed for a cycle of $14 \mathrm{~h}$ of light $\left(100 \mu \mathrm{E} \mathrm{m}^{-2} \mathrm{~s}^{-1}\right)$ and $10 \mathrm{~h}$ of darkness on an equal combination of commercially available radish (Early scarlet globe) and mustard (Florida broadleaf). Arabidopsis plants were cultivated at $22^{\circ} \mathrm{C}$ in a growth chamber programmed for a cycle of $14 \mathrm{~h}$ of light $\left(100 \mu \mathrm{E} \mathrm{m}^{-2} \mathrm{~s}^{-1}\right)$ and $10 \mathrm{~h}$ of darkness.

The ssi2 mutant (Shah et al. 2001) and NahG transgenic (Shah et al. 1999) plants are in the Arabidopsis accession Nössen, the pad4-1 mutant (TAIR seed stock CS3806) is in the accession Columbia, and the PAD4 (overexpression) line, in which the PAD4 cDNA is expressed from the Cauliflower mosaic virus 35S gene promoter (Pegadaraju et al. 2007), is in the accession Wassileskija. The $s s i 2$ nah $G$ plant has been previously described (Shah et al. 2001). To generate the ssi2 pad4 doublemutant plant, pollen from the ssi2 plant was used to pollinate pad4-1 flowers. F2 progeny derived from the F1 hybrids were genotyped with a cleaved amplified polymorphic sequence (CAPS) marker that distinguishes the WT from the pad4-1 allele, and a dCAPS marker that distinguishes the WT from the ssi2 allele (discussed below). F3 progeny derived from two lines (nos. 2 and 4) doubly homozygous for the ssi2 and pad41 mutant alleles were used in this study. These F3 plants exhibit spontaneous cell death and are dwarfs compared with the WT. However, they are marginally larger than the ssi2 mutant plant. Phenotypic characterization of a similar ssi2 pad4 double-mutant line was previously described (Nandi et al. 2005).

For the experiment outlined in Figure 1C, F2 progeny derived from an F1 hybrid (ssi2/+ pad4-1/+) were genotyped for the allele configuration at the PAD4 and SSI2 loci after completion of the no-choice bioassay. These aphid-infested plants were subsequently destroyed.

\section{No-choice and choice tests.}

All bioassays were conducted at $22^{\circ} \mathrm{C}$ in a growth chamber programmed for a cycle of $14 \mathrm{~h}$ of light $\left(100 \mu \mathrm{E} \mathrm{m}^{-2} \mathrm{~s}^{-1}\right)$ and $10 \mathrm{~h}$ of darkness. For the no-choice bioassays, each genotype was planted in separate pots, two plants per pot. These pots were randomly arranged in the growth chamber. Twenty mature apterous (wingless) aphids were introduced on each approximately 4-week-old Arabidopsis plant and the numbers of aphids (adults + nymphs) on each plant were counted 2 days after release. For the choice tests, each pot contained one WT and one ssi 2 mutant plant. The experiment was initiated when plants were approximately 4 weeks old by releasing 20 adult apterous insects at the center of each pot, equidistant from the WT and the ssi2 mutant plant. The numbers of adult GPA on each plant were counted at various time points after release of the insects. For both the no-choice and choice assays, the rim of each pot was wrapped in a tape, with the sticky side facing toward the plants to prevent pot-to-pot migration of insects.

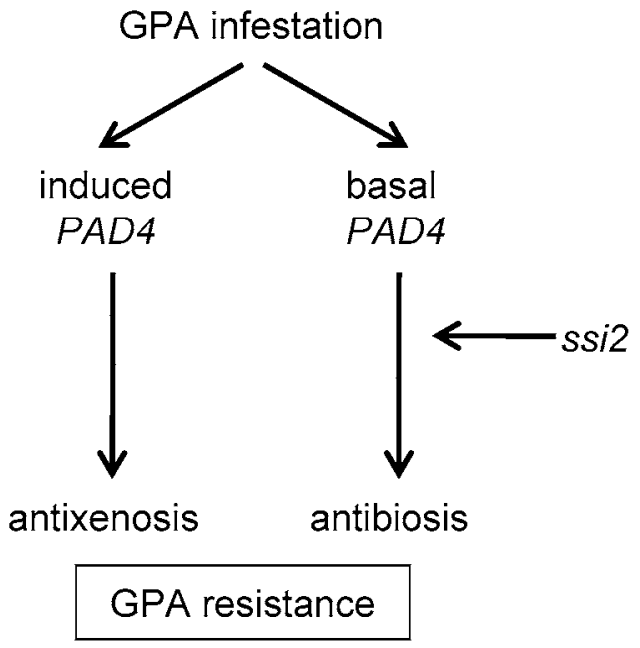

Fig. 8. Model depicting the impact of the suppressor of salicylic acid insensitivity2 (ssi2) mutation on PHYTOALEXIN DEFICIENT4 (PAD4) involvement in plant defense against green peach aphid (GPA). PAD4 is required for antixenosis and antibiosis against GPA. According to this model, basal expression of $P A D 4$ in wild-type (WT) plants contributes to antibiosis, and the GPA infestation-induced expression of PAD4 contributes to antixenosis. These suggestions are based on the fact that, compared with the WT, petiole exudate collected from the uninfested pad4 mutant lacks an antibiotic activity, and constitutive overexpression of PAD4 transcript does not result in any increase in antibiosis, although it does enhance antixenosis (Pegadaraju et al. 2007). In the ssi2 mutant, the PAD4-determined antibiosis activity is elevated. However, antixenotic defenses are not affected in the ssi2 mutant. Basal and GPA-induced expression of PAD4 is comparable between the ssi2 mutant and WT. Hence, the ssi2 mutation is depicted to stimulate a step downstream of PAD4 transcript accumulation, specifically affecting PAD4 protein's participation in the antibiosis mechanism, but not antixenosis. 
Aphid feeding behavior.

EPG technique was utilized to determine the feeding behavior of GPA, as previously described (Pegadaraju et al. 2007). Twenty replications were performed for the Arabidopsis WT (Nö) and ssi2 mutant plant. The mean time spent by GPA on various activities was analyzed by the nonparametric KruskalWallis test $(P<0.05)$.

\section{Petiole exudate collection.}

The collection of petiole exudates, enriched in phloem exudates from Arabidopsis leaves, was done using a previously described method (Chaturvedi et al. 2008). For each replication, a minimum of 80 to 120 leaves from 26 to 32 plants (each of WT or mutant) were used to collect the petiole exudates.

\section{Feeding trials.}

All feeding trial bioassays were conducted at $22^{\circ} \mathrm{C}$ in a growth chamber programmed for a cycle of $14 \mathrm{~h}$ of light (100 $\left.\mu \mathrm{E} \mathrm{m} \mathrm{m}^{-2} \mathrm{~s}^{-1}\right)$ and $10 \mathrm{~h}$ of darkness. The aphids were placed on a synthetic diet (Mittler and Dadd 1965) mixed with either the WT or mutant plant petiole exudates, obtained using the technique described by Chaturvedi and associates (2008) or chemicals. Three adult GPA were transferred with a fine paintbrush onto a feeding chamber (Falcon, Primaria, NJ, U.S.A.). A layer of stretched parafilm (Parafilm "M"; American National Can, Greenwich, CT, U.S.A.) was placed over the chamber. Then, $500 \mu \mathrm{l}$ of aphid diet with or without supplementation by petiole exudates or chemicals was added and a second layer of stretched parafilm was placed to form a feeding sachet through which the aphids could feed on the diet. Aphids were allowed to feed on the diet and the aphid population size determined 4 days later. In each experiment, three repeats were included for treatment.

In the synthetic diet bioassays, which were initiated with three insects per feeding chamber, by 4 days postinfestation (dpi) there was a significant increase in GPA population, without overcrowding, thus allowing quantitative differences in insect numbers on diets containing petiole exudates from plants of different genotypes to be reproducibly measured. In contrast, in the no-choice bioassays, which were initiated with 20 insects per plant, at 4 dpi a large number of insects had migrated away from the plant, as determined by the number of insects found trapped on the tape at the rim of the pots. Hence, the no-choice bioassays were terminated at $2 \mathrm{dpi}$, when a significant increase in GPA population was observed on the WT plants, thus permitting quantitative differences in insect numbers on plants of two genotypes to be reproducibly measured.

\section{FA and SA treatment for synthetic diet bioassay.}

FA and sodium salicylate dissolved in $0.1 \%$ methanol $(\mathrm{MeOH})$ were diluted in water or the aphid diet to give the requisite concentrations for feeding trials.

\section{FA application to plants.}

FA solutions in $0.1 \% \mathrm{MeOH}$ were infiltrated into the abaxial surface of Arabidopsis leaves. Control plants were treated with $0.1 \% \mathrm{MeOH}$. At $6 \mathrm{~h}$ after treatment, 20 adult apterous aphids were released on each plant and no-choice tests were performed with these plants as previously described (Pegadaraju et al. 2005).

\section{DNA extraction and PCR analysis.}

Genomic DNA from Arabidopsis leaf tissue was isolated as previously described (Konieczny and Ausubel 1993). A previously described PCR-based dCAPS was used to distinguish between the SSI2 and ssi2 alleles (Chaturvedi et al. 2008). The primers SSI2-dCAPS-F (5'-TTGTTTTGGTGGGGGACATGA TCACAGAAGGTGCA-3') and SSI2-dCAPS-R (5'-TCGAT
CTGCCTCATGTCAACACG-3') were used for the PCR. PCR conditions were $95^{\circ} \mathrm{C}$ for $5 \mathrm{~min}$; followed by 35 cycles of $95^{\circ} \mathrm{C}$ for $30 \mathrm{~s}, 62^{\circ} \mathrm{C}$ for $45 \mathrm{~s}$, and $72^{\circ} \mathrm{C}$ for $45 \mathrm{~s}$; with a final extension at $72^{\circ} \mathrm{C}$ for $5 \mathrm{~min}$. The resulting 200-bp PCR product was treated with $A p a \mathrm{~L} 1$ (New England Biolabs). Restriction of the WT SSI2 amplicon by ApaL1 yielded a characteristic 175bp fragment. In contrast, the ssi 2 amplicon was not cleaved by ApaL1. CAPS analysis was similarly used to distinguish the WT PAD4 and the pad4-1 allele, as described previously (Heck et al. 2003). The primers PAD4-CAPS-F (5'-GCGATGCATCA GAAGAG- $3^{\prime}$ ) and PAD4-CAPS-R (5'-TTAGCCCAAAAGCA AGTATC- $3^{\prime}$ ) were used for PCR to yield an approximately 391bp product. PCR conditions were as follows: $95^{\circ} \mathrm{C}$ for $5 \mathrm{~min}$; followed by 30 cycles of $95^{\circ} \mathrm{C}$ for $30 \mathrm{~s}, 55^{\circ} \mathrm{C}$ for $45 \mathrm{~s}$, and $72^{\circ} \mathrm{C}$ for $45 \mathrm{~s}$; with a final extension at $72^{\circ} \mathrm{C}$ for $5 \mathrm{~min}$. Restriction of the WT PAD4 amplicon by BsmF1 (New England Biolabs) yielded a characteristic 110-bp product. The pad4-1 mutant amplicon was not cleaved by BsmF1.

\section{RNA extraction and RT-PCR analysis.}

RNA for RT-PCR analysis was extracted from Arabidopsis leaves as previously described (Pegadaraju et al. 2005). A twostep RT-PCR was performed on RNA samples as previously described (Pegadaraju et al. 2007). Gene-specific PCR primers (Supplementary Table 2) for ACT8 (At1g49240), PAD4 (At3g52430), SAG13 (At2g29350), SAG21 (At4g02380), and SAG27 (At3g44300) were used. ACT8 provided a control for RT-PCR. PCR conditions for Figure 1A were as follows: $95^{\circ} \mathrm{C}$ for $5 \mathrm{~min}$; followed by 25 cycles of $95^{\circ} \mathrm{C}$ for $30 \mathrm{~s}, 55^{\circ} \mathrm{C}$ for 45 $\mathrm{s}$, and $72^{\circ} \mathrm{C}$ for $1 \mathrm{~min}$; with a final extension at $72^{\circ} \mathrm{C}$ for 5 min. PCR conditions for Figure 2 were as follows: $95^{\circ} \mathrm{C}$ for 5 min; followed by 30 cycles of $95^{\circ} \mathrm{C}$ for $30 \mathrm{~s}, 55^{\circ} \mathrm{C}$ for $45 \mathrm{~s}$, and $72^{\circ} \mathrm{C}$ for $1 \mathrm{~min}$; with a final extension at $72^{\circ} \mathrm{C}$ for $7 \mathrm{~min}$.

\section{ACKNOWLEDGMENTS}

We thank J. Higgins and J. Parker for statistical analysis and providing seed to the Arabidopsis transgenic PAD4 overexpression line, respectively. This work was supported at different times by grants from the Cooperative State Research, Education, and Extension Service, United States Department of Agriculture (agreement 2004-35301-18999), and the National Science Foundation (MCB-0455318 and IOS-0919192).

\section{LITERATURE CITED}

Baker, J. R. 1994. Insect and related pests of flowers and foliage plants: Some important, common, and potential pests in the southeastern United States. Revised ed. North Carolina Cooperative Extension Service Publication AG-136. Raleigh, NC, U.S.A.

Blackman, R. L., and Eastop, V. F. 2000. Aphids on the World's Crops. John Wiley \& Sons, Chichester, U.K.

Bush, J., Jander, G., and Ausubel, F. M. 2006. Prevention and control of pests and diseases. Pages 13-25 in: Arabidopsis Protocols, 2nd ed. J. Salinas and J. J. Sanchez-Serrano, eds. Humana Press, Totowa, NJ, U.S.A.

Cabrera y Poch, H. L., Ponz, F., and Fereres, A. 1998. Searching for resistance in Arabidopsis thaliana to the green peach aphid Myzus persicae. Plant Sci. 138:209-216.

Chaturvedi, R., Krothapalli, K., Makandar, R., Nandi, A., Sparks, A. A., Roth, M. R., Welti, R., and Shah, J. 2008. Plastid $\omega$-3-fatty acid desaturase-dependent accumulation of a systemic acquired resistance inducing activity in petiole exudates of Arabidopsis thaliana is independent of jasmonic acid. Plant J. 54:106-117.

Cherqui, A., and Tjallingii, W. F. 2000. Salivary proteins of aphids, a pilot study on identification, separation and immunolocalisation. J. Insect Physiol. 46:1177-1186.

Couldridge, C., Newbury, H. J., Fort-Lloyd, B., Bale, J., and Pritchard, J. 2007. Exploring plant responses to aphid feeding using a full Arabidopsis microarray reveals a small number of genes with significantly altered expression. Bull. Entomol. Res. 97:523-532.

de Vos, M., Kim, J. K., and Jander, G. 2007. Biochemistry and molecular biology of Arabidopsis-aphid interactions. BioEssays 29:871-883. 
Goggin, F. L. 2007. Plant-aphid interactions: Molecular and ecological perspectives. Curr. Opin. Plant Biol. 10:399-408.

Halkier, B. A., and Gershenzon, J. 2006. Biology and biochemistry of glucosinolates. Annu. Rev. Plant Biol. 57:303-333.

Heck, S., Grau, T., Buchala, A., Métraux, J.-P., and Nawrath, C. 2003. Genetic evidence that expression of $\mathrm{NahG}$ modifies defence pathways independent of salicylic acid biosynthesis in the Arabidopsis-Pseudomonas syringae pv. tomato interaction. Plant J. 36:342-352.

Kachroo, P., Shanklin, J., Shah, J., Whittle, E. J., and Klessig, D. F. 2001. A fatty acid desaturase modulates the activation of defense signaling pathways in plants. Proc. Natl. Acad. Sci. U.S.A. 98:9448-9453.

Kachroo, A., Venugopal, S. C., Lapchyk, L., Falcone, D., Hildebrand, D., and Kachroo, P. 2004. Oleic acid levels regulated by glycerolipid metabolism modulate defense gene expression in Arabidopsis. Proc. Natl. Acad. Sci. U.S.A. 101:5152-5157.

Kennedy, J. S., Day, M. F., and Eastop, V. F. 1962. A Conspectus of Aphids as Vectors of Plant Viruses. Commonwealth Institute of Entomology, London.

Kim, J. H., and Jander, G. 2007. Myzus persicae (green peach aphid) feeding on Arabidopsis induces the formation of a deterrent indole glucosinolate. Plant J. 49:1008-1019.

Kim, J. H., Lee, B. W., Schroeder, F. C., and Jander, G. 2008. Identification of indole glucosinolate breakdown products with antifeedant effects on Myzus persicae (green peach aphid). Plant J. 54:1015-1026.

Kliebenstein, D. J., Figuth, A., and Mitchell-Olds, T. 2002. Genetic architecture of plastic methyl jasmonate responses in Arabidopsis thaliana. Genetics 161:1685-1696.

Klingauf, F. A. 1987. Host plant finding and acceptance. Pages 209-223 in: Aphids: Their Biology, Natural Enemies and Control, Vol. A. A. K. Minks and P. Harrewijn, eds. Elsevier, Amsterdam.

Konieczny, A., and Ausubel, F. M. 1993. A procedure for mapping Arabidopsis mutations using co-dominant ecotype-specific PCR based markers. Plant J. 4:403-410.

Lattanzio, V., Arpaia, S., Cardinali, A., Di Venere, D., and Linsalata, V. 2000. Role of endogenous flavonoids in resistance mechanism of Vigna to Aphids. J. Agric. Food Chem. 48:5316-5320.

Mewis, I., Tokuhisa, J. G., Schultz, J. C., Appel, H. M., Ulrichs, C., and Gershenzon, J. 2006. Gene expression and glucosinolate accumulation in Arabidopsis thaliana in response to generalist and specialist herbivores of different feeding guilds and the role of defense signaling pathways. Phytochemistry 67:2450-2462.

Mikkelsen, M. D., Petersen, B. L., Glawischnig, E., Jensen, A. B., Andreasson, E., and Halkier, B. A. 2003. Modulation of CYP79 genes and glucosinolates profiles in Arabidopsis by defense signaling pathways. Plant Physiol. 131:298-308.

Mikkelsen, M. D., Naur, P., and Halkier, B. A. 2004. Arabidopsis mutants in the C-S lyase of glucosinolates biosynthesis establish a critical role in indole-3-acetaldoxime in auxin homeostasis. Plant J. 37:770-777.

Miles, P. W. 1999. Aphid saliva. Biol. Rev. Cambridge Philos. Soc. 74:4185.

Mittler, T. E., and Dadd, R. H. 1965. Differences in the probing responses of Myzus persicae (Sülzer) elicited by different feeding solutions behind a parafilm membrane. Entomol. Exp. Appl. 8:107-122.

Mutti, N. S., Louis, J., Pappan, L. K., Pappan, K., Begum, K., Chen, M. S. Park, Y., Dittmer, N., Marshall, J., Reese, J. C., and Reeck, G. R. 2008. A protein from the salivary glands of the pea aphid, Acyrthosiphon pisum, is essential in feeding on a host plant. Proc. Natl. Acad. Sci. U.S.A. 105:9965-9969.

Nandi, A., Krothapalli, K., Buseman, C., Li, M., Welti, R., Enyedi, A., and Shah, J. 2003. The Arabidopsis thaliana sfd mutants affect plastidic lipid composition and suppress dwarfing, cell death and the enhanced disease resistance phenotypes resulting from the deficiency of a fatty acid desaturase. Plant Cell 15:2383-2398.

Nandi, A., Moeder, W., Kachroo, P., Klessig, D.F., and Shah, J. 2005. The Arabidopsis ssi2-conferred susceptibility to Botrytis cinerea is dependent on EDS5 and PAD4. Mol. Plant-Microbe Interact. 18:363-370.

Park, S.-J., Huang, Y., and Ayoubi, P. 2005. Identification of expression profiles of sorghum genes in response to greenbug phloem-feeding using cDNA subtraction and microarray analysis. Planta 223:932-947.

Pegadaraju, V. 2005. Molecular insights into Arabidopsis response to Myzus persicae Sülzer (green peach aphid). Ph.D. thesis, Kansas State University, Manhattan, U.S.A.

Pegadaraju, V., Knepper, C., Reese, J. C., and Shah, J. 2005. Premature leaf senescence modulated by the Arabidopsis PAD4 gene is associated with defense against the phloem-feeding green peach aphid. Plant Physiol. 139:1927-1934.

Pegadaraju, V., Louis, J., Singh, V., Reese, J., Bautor, J., Feys, B., Cook, G., Parker, J., and Shah, J. 2007. Phloem-based resistance to green peach aphid is controlled by Arabidopsis PHYTOALEXIN DEFICIENT4 without its signaling partner ENHANCED DISEASE SUSCEPTIBILITY1. Plant J. 52:332-341.

Pedigo, L. P. 1999. In: Entomology and Pest Management, 3rd ed. Prentice-Hall, Englewood Cliffs, NJ, U.S.A.

Powell, G., Tosh, C. R., and Hardie, J. 2006. Host plant selection by aphids: Behavioral, evolutionary and applied perspectives. Annu. Rev. Entomol. 51:309-330.

Ribeiro, A. P. O., Pereira, E. J. G., Galvan, T. L., Picanco, M. C., Picoli, E A. T., da Silva, D. J. H., Fari, M. G., and Otoni, W. C. 2006. Effect of eggplant transformed with oryzacystatin gene on Myzus persicae and Macrosiphum euphorbiae. J. Appl. Entomol. 130:84-90.

Sekine, K. T., Nandi, A., Ishihara, T., Hase, S., Ikegami, M., Shah, J., and Takahashi, H. 2004. Enhanced resistance to Cucumber mosaic virus in the Arabidopsis thaliana ssi2 mutant is mediated via an SA-independent mechanism. Mol. Plant-Microbe Interact. 17:623-632.

Shah, J., Kachroo, P., and Klessig, D. F. 1999. The Arabidopsis ssil mutation restores pathogenesis-related gene expression in nprl plants and renders defensin gene expression SA dependent. Plant Cell 11:191-206.

Shah, J., Kachroo, P., Nandi, A., and Klessig, D. F. 2001. A recessive mutation in the Arabidopsis SSI2 gene confers SA- and NPR1-independent expression of $P R$ genes and resistance against bacterial and oomycete pathogens. Plant J. 25:563-574.

Smith, C. M. 2005. Plant Resistance to Arthropods: Molecular and Conventional Approaches. Springer, The Netherlands.

Smith, C. M., and Boyko, E. V. 2007. The molecular bases of plant resistance and defense responses to aphid feeding: Current status. Entomol. Exp. Appl. 122:1-16.

Sylwia, G., Bogumil, L., and Wieslaw, O. 2006. Effect of low and highsaponin lines of alfalfa on pea aphid. J. Insect Physiol. 52:737-743.

Tjallingii, W. F. 1988. Electrical recording of stylet penetration activities. Pages 95-108 in: Aphids, Their Biology, Natural Enemies and Control A. K. Minks and P. Harrewijn, eds. Elsevier, Amsterdam.

Tjallingii, W. F. 2006. Salivary secretions by aphids interacting with proteins of phloem wound responses. J. Exp. Bot. 57:739-745.

Tjallingii, W. F., and Esch, T. H. 1993. Fine-structure of aphid stylet routes in plant-tissues in correlation with EPG signals. Physiol. Entomol. 18:317-328.

Unwin, F. M. 1978. A versatile high-frequency microcautery. Physiol. Entomol. 3:71-73

Urbanska, A., Tjallingii, W.F., Dixon, A. F. G., and Leszczynski, B. 1998. Phenol oxidizing enzymes in the grain aphid's saliva. Entomol. Exp. Appl. 86:197-203.

Walker, G. P. 2000. A beginner's guide to electronic monitoring of homopteran probing behavior. Pages 14-40 in: Principles and Applications of Electronic Monitoring and Other Techniques in the Study of Homopteran Feeding Behavior. G. P. Walker and E. A. Backus, eds. Thomas Say Publications in Entomology, Entomology Society of America, Lanham, MD, U.S.A.

Walling, L. L. 2008. Avoiding effective defenses: Strategies employed by phloem-feeding insects. Plant Physiol. 146:859-866.

Wang, C., and Wang, X. 2001. A novel phospholipase D of Arabidopsis that is activated by oleic acid and associated with the plasma membrane. Plant Physiol. 127:1102-1112.

Will, T., Tjallingii, W. F., Thonnessen, A., and van Bel, A. J. E. 2007. Molecular sabotage of plant defense by aphid saliva. Proc. Natl. Acad. Sci. U.S.A. 104:10536-10541.

Wu, J., Luo, X., Guo, H., Xiao, J., and Tian, Y. 2006. Transgenic cotton, expressing Amaranthus caudatus agglutinin, confers enhanced resistance to aphids. Plant Breed. 125:390-394.

Zhu, X., Shaw, P. N., Pritchard, J., Newbury, J., Hunt, E. J., and Barrett, D. A. 2005. Amino acid analysis by micellar electrokinetic chromatography with laser-induced fluorescence detection: Application to nanolitrevolume biological samples from Arabidopsis thaliana and Myzus persicae. Electrophoresis 26:911-919.

\section{AUTHOR-RECOMMENDED INTERNET RESOURCE}

New England Biolabs website: www.neb.com 